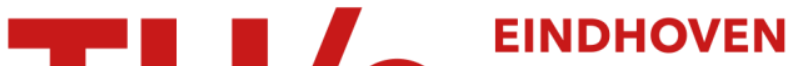 UNIVERSITY OF TECHNOLOGY
}

\section{Coverage effects in $\mathrm{CO}$ dissociation on metallic cobalt nanoparticles}

Citation for published version (APA):

Zijlstra, B., Broos, R., Chen, W., Oosterbeek, H., Filot, I., \& Hensen, E. (2019). Coverage effects in CO dissociation on metallic cobalt nanoparticles. ACS Catalysis, 9(8), 7365-7372.

https://doi.org/10.1021/acscatal.9b01967

DOI:

10.1021/acscatal.9b01967

Document status and date:

Published: 02/08/2019

Document Version:

Publisher's PDF, also known as Version of Record (includes final page, issue and volume numbers)

Please check the document version of this publication:

- A submitted manuscript is the version of the article upon submission and before peer-review. There can be important differences between the submitted version and the official published version of record. People interested in the research are advised to contact the author for the final version of the publication, or visit the $\mathrm{DOI}$ to the publisher's website.

- The final author version and the galley proof are versions of the publication after peer review.

- The final published version features the final layout of the paper including the volume, issue and page numbers.

Link to publication

\section{General rights}

Copyright and moral rights for the publications made accessible in the public portal are retained by the authors and/or other copyright owners and it is a condition of accessing publications that users recognise and abide by the legal requirements associated with these rights.

- Users may download and print one copy of any publication from the public portal for the purpose of private study or research.

- You may not further distribute the material or use it for any profit-making activity or commercial gain

- You may freely distribute the URL identifying the publication in the public portal.

If the publication is distributed under the terms of Article 25fa of the Dutch Copyright Act, indicated by the "Taverne" license above, please follow below link for the End User Agreement:

www.tue.nl/taverne

Take down policy

If you believe that this document breaches copyright please contact us at:

openaccess@tue.nl

providing details and we will investigate your claim. 


\title{
Coverage Effects in CO Dissociation on Metallic Cobalt Nanoparticles
}

\author{
Bart Zijlstra, ${ }^{\dagger}$ Robin J. P. Broos, ${ }^{\dagger}{ }^{\oplus}$ Wei Chen, ${ }^{\dagger}$ Heiko Oosterbeek, ${ }^{\dagger}$ Ivo A. W. Filot, \\ and Emiel J. M. Hensen*, ${ }^{+}$ \\ ${ }^{\dagger}$ Laboratory of Inorganic Materials \& Catalysis, Schuit Institute of Catalysis, Department of Chemical Engineering and Chemistry, \\ Eindhoven University of Technology, P. O. Box 513, 5600 MB Eindhoven, The Netherlands \\ "Shell Global Solutions International B.V., Grasweg 31, $1031 \mathrm{HW}$ Amsterdam, The Netherlands
}

Supporting Information

ABSTRACT: The active site of $\mathrm{CO}$ dissociation on a cobalt nanoparticle, relevant to the Fischer-Tropsch reaction, can be computed directly using density functional theory. We investigate how the activation barrier for direct $\mathrm{CO}$ dissociation depends on $\mathrm{CO}$ coverage for step-edge and terrace cobalt sites. Whereas on terrace sites increasing coverage results in a substantial increase of the direct $\mathrm{CO}$ dissociation barrier, we find that this barrier is nearly independent of $\mathrm{CO}$ coverage for the step-edge sites on corrugated surfaces. A detailed electronic analysis shows that this difference is due to the flexibility of the adsorbed layer, minimizing Pauli repulsion during the carbonoxygen bond dissociation reaction on the step-edge site. We constructed a simple first-principles microkinetic model that not only reproduces experimentally observed rates but also shows how migration of carbon species between step-edge and terrace sites contributes to methane formation.

KEYWORDS: Fischer-Tropsch synthesis, DFT, microkinetic modeling, lateral interactions, activation energy

\section{INTRODUCTION}

The design of heterogeneous catalysts from first principles remains passionately sought after. This formidable task hinges on fundamental understanding of catalytic action through molecular insight into the chain of elementary reaction steps proceeding on the surface of heterogeneous catalysts. The three paradigmatic laws of catalysis were formulated by Berzelius, Ostwald, and Sabatier. ${ }^{1}$ Of these, Sabatier's principle is most helpful for predicting the composition of optimum catalysts. Sabatier postulated that reaction complexes formed between the catalyst and the reactant should be neither too strong nor too weak. With the advent of modern quantumchemical methods and increased computational power, this led to the formulation of scaling laws that link catalyst composition to performance. ${ }^{2-5}$ The state of the art in computational catalysis is to explore the potential energy surface between reactants and products using density functional theory. Using Eyring's transition state theory, ${ }^{6}$ these data can be used to make predictions about conversion rates and product distribution by, for instance, microkinetics simulations. ${ }^{7,8}$ Such simulations are usually based on the assumption of a Langmuir surface characterized by one type of sites. ${ }^{9}$ There are, however, many instances in heterogeneous catalysis that warrant an alternative Taylorian view of surface reactivity. ${ }^{10}$ That is to say that catalysis occurs by uniquely active sites that are sometimes present only in very small numbers. Important examples are the hydrogenation of dinitrogen to ammonia (Haber-Bosch process) and the hydrogenation of carbon monoxide to liquid hydrocarbons (Fischer-Tropsch process). It remains unclear if and how low-reactive sites influence the ongoing catalytic reaction. While the importance of stepped sites is well-accepted for the dissociation of dinitrogen, ${ }^{11}$ there remains considerable debate about the nature of active sites for carbon monoxide dissociation, which is an essential step in Fischer-Tropsch (FT) synthesis. A key aspect of this ongoing discussion is the role of lateral interactions on the usually crowded surfaces. In particular, in the context of FT synthesis, high $\mathrm{CO}$ coverages encountered at reaction conditions are expected to substantially raise the barrier of $\mathrm{CO}$ dissociation. $^{12,13}$ This would favor alternative pathways for $\mathrm{CO}$ dissociation and chain growth in the FT synthesis process.

Gas-to-liquid processes are gaining in importance as natural gas is increasingly used for the production of clean transportation fuels and chemicals in the Fischer-Tropsch (FT) process. $^{14-17}$ It is of significant fundamental and practical interest to understand the molecular details underlying FT

Received: May 13, 2019

Revised: July 2, 2019

Published: July 5, 2019 

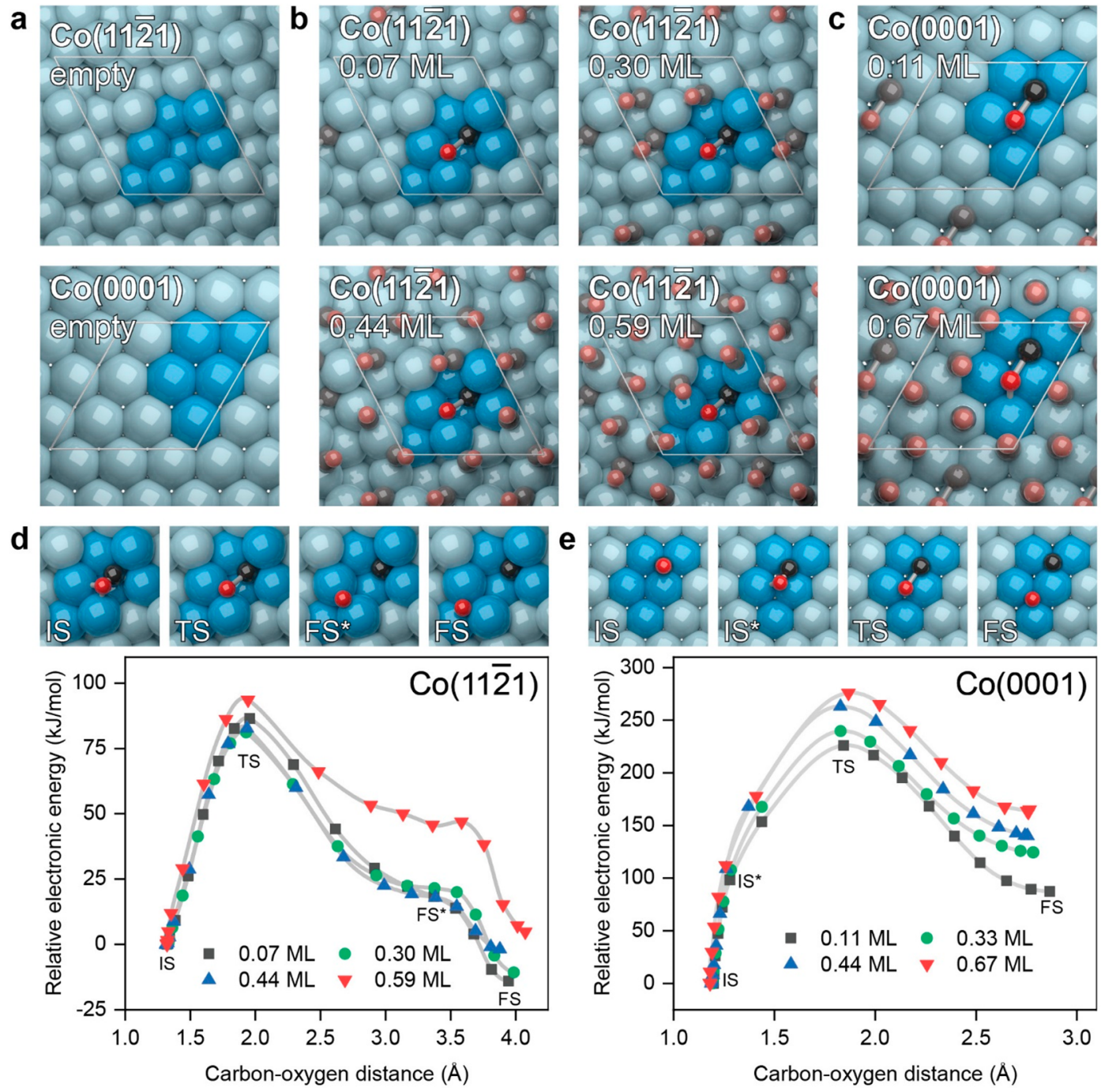

Figure 1. Top surface views of empty and $\mathrm{CO}$-covered $\mathrm{Co}(0001)$ and $\mathrm{Co}(11 \overline{2} 1)$, the most favorable $\mathrm{CO}$ dissociation pathways, and the associated potential energy surface as a function of the reaction coordinate ( $\mathrm{C}-\mathrm{O}$ bond distance): (a) empty surfaces; (b) transition states on $\mathrm{Co}(11 \overline{2} 1)$ at CO coverages of 0.07, 0.30, 0.44, and 0.59 ML (other coverages in the Supporting Information); (c) transition states on Co(0001) at 0.11 and 0.67 $\mathrm{ML}$; (d, e) CO dissociation pathway and energetics for $(\mathrm{d}) \mathrm{Co}(11 \overline{2} 1)$ and (e) $\mathrm{Co}(0001)$ : the top panels show the initial state (IS), the transition state (TS), and the final state (FS) for CO dissociation at the lowest CO coverage. FS* is a metastable state with the O atom bridge-bonded. IS* is the state after rotation of the $\mathrm{CO}$ without significantly increasing the $\mathrm{C}-\mathrm{O}$ distance.

synthesis catalyzed by metal nanoparticles. $\mathrm{CO}$ dissociation is a crucial elementary reaction step within the FT mechanism. Depending on catalyst choice and reaction conditions, the $\mathrm{CO}$ dissociation step can contribute to the degree of rate control in various amounts. ${ }^{7}$ A prerequisite for obtaining long-chain hydrocarbons is a high supply rate of $\mathrm{C}_{1}$ monomers. ${ }^{18-21} \mathrm{~A}$ common view is that low-barrier $\mathrm{CO}$ dissociation requires step-edge sites, which can explain the experimentally observed strong structure sensitivity of the FT reaction. ${ }^{22}$ Optimum FT catalysts comprise Co nanoparticles with a size of $\sim 6 \mathrm{~nm}$, because smaller particles cannot accommodate a sufficient amount of step-edge sites. ${ }^{23-25}$ Typical activation barriers for direct $\mathrm{CO}$ dissociation computed by density functional theory (DFT) are in the range of $100-150 \mathrm{~kJ} / \mathrm{mol}$ for most stepped Co surfaces. ${ }^{26,27}$ Lower barriers are reported for $\mathrm{Ru}$ surfaces. $^{28,29}$ These values should be contrasted with barriers higher than $200 \mathrm{~kJ} / \mathrm{mol}$ for direct dissociation of CO on closepacked surfaces. $\mathrm{H}$-assisted $\mathrm{CO}$ dissociation pathways have also been explored. ${ }^{28-31}$ Although barriers for $\mathrm{C}-\mathrm{O}$ bond cleavage in adsorbed $\mathrm{HCO}, \mathrm{H}_{2} \mathrm{CO}$, and $\mathrm{HCOH}$ intermediates are lower than that for adsorbed $\mathrm{CO}$, these hydrogenated surface intermediates are typically much less stable. ${ }^{32,33}$ Therefore, overall barriers for $\mathrm{H}$-assisted $\mathrm{CO}$ dissociation are usually higher than those for direct $\mathrm{CO}$ dissociation on stepedge sites. For example, Filot et al. found a direct $\mathrm{CO}$ dissociation barrier of $173 \mathrm{~kJ} / \mathrm{mol}$ on $\mathrm{Rh}(211)$, while the overall barriers via $\mathrm{HCO}$ and $\mathrm{COH}$ are 263 and $275 \mathrm{~kJ} / \mathrm{mol}$, respectively. ${ }^{34}$ Shetty et al. reported an overall barrier for $\mathrm{HCO}$ dissociation on $\mathrm{Ru}(11 \overline{2} 1)$ of $120 \mathrm{~kJ} / \mathrm{mol}$, whereas the direct CO scission is only $65 \mathrm{~kJ} / \mathrm{mol}$ on the same site. ${ }^{29}$ Liu et al. concluded that face-centered cubic (FCC) cobalt catalysts and hexagonal close-packed (HPC) cobalt terraces prefer the $\mathrm{H}$ assisted route $(125 \mathrm{~kJ} / \mathrm{mol}$ on $\mathrm{Co}(110))$, while corrugated HCP cobalt catalysts have remarkably higher intrinsic activity via a preferred direct dissociation route $(103 \mathrm{~kJ} / \mathrm{mol}$ on $\left.\operatorname{Co}\left(11 \frac{1}{2} 1\right)\right)^{27,35}$

Although all these studies suggest a FT mechanism dominated by direct $\mathrm{CO}$ dissociation, significant changes in 
reaction kinetics can be expected due to carbon-induced deactivation $^{36-38}$ and lateral interactions from high surface coverage. $^{12,13,39}$ As both effects could block facile pathways for direct $\mathrm{CO}$ dissociation, the mechanism is expected to shift to an $\mathrm{H}$-assisted mechanism. CO-scrambling experiments, however, contradict this. ${ }^{40} \mathrm{CO}$-scrambling rates on a cobalt FT catalyst were found to be fast, even without hydrogen. Moreover, it has been demonstrated that carbon deposition on a cobalt FT catalyst occurs mainly on terrace surfaces, and, at low concentrations, it does not affect FT activity. ${ }^{15}$ This implies that $\mathrm{C}$ atoms generated on step-edge sites are involved in chain-growth reactions and, therefore, do not block the stepedge sites.

Both experimental surface science data ${ }^{41,42}$ and DFT modeling $^{12,43}$ of $\mathrm{CO}$ adsorption show that the $\mathrm{CO}$ saturation coverage for the $\mathrm{Co}(0001)$ surface is about 7/12 ML. Experimental steady-state isotopic transient kinetic analysis (SSITKA) data show that the CO coverage is between 0.4 and 0.6 ML under model FT conditions, ${ }^{19,44,45}$ in good agreement with extrapolated surface science data. ${ }^{42}$ On the other hand, Loveless et al. used DFT modeling to demonstrate that a higher than $1 \mathrm{ML}$ CO coverage is possible on a cluster of 201 $\mathrm{Ru}$ atoms. ${ }^{13}$ These authors showed that the $\mathrm{CO}$ dissociation barrier on a $(1 \overline{1} 05)$ step-edge site with a CO coverage of 1.07 $\mathrm{ML}$ is close to $150 \mathrm{~kJ} / \mathrm{mol}$, much higher than the barrier on a $\mathrm{Ru}(11 \overline{2} 1)$ step-edge at low coverage. Thus, a high coverage might lead to an increased CO dissociation barrier. Neurock, Iglesia, and co-workers alternatively emphasized the role of $\mathrm{H}$ and also $\mathrm{H}_{2} \mathrm{O}$-promoted pathways for $\mathrm{CO}$ dissociation on the terrace surfaces that dominate nanoparticles. ${ }^{39,46,47}$ A critique on these works mentions that the high coverage computed to be possible on a $\mathrm{Ru}_{201}$ cluster is mainly caused by expansion and restructuring of the relatively small cluster. ${ }^{48}$ In addition to this, we computed the activation barrier for $\mathrm{CO}$ dissociation on the $\mathrm{Co}(1 \overline{1} 05)$ surface at low coverage (see the Supporting Information). The computed value of $151 \mathrm{~kJ} / \mathrm{mol}$ obtained at low coverage is also high, suggesting that the particular stepedge geometry used in the work of Neurock and Iglesia is not very favorable for $\mathrm{CO}$ dissociation. High $\mathrm{CO}$ coverages are expected to destabilize adsorbed hydrogen, which might lower the barrier for $\mathrm{HCO}$ formation. If this effect can significantly reduce the overall barrier for $\mathrm{HCO}$ dissociation on step-edges, then this pathway can compete with direct $\mathrm{CO}$ scission. Whether this happens depends on the amount of destabilization of the formed HCO. Su et al. considered the effect of a 7/ $12 \mathrm{ML}$ CO coverage on the FT mechanism on Co(0001) and found that steric hindrance contributes to additional repulsive interactions on $\mathrm{HCO}$ compared to $\mathrm{CO} .{ }^{49}$ From this data we deduce that the combined effect is a relatively constant overall barrier for HCO formation and dissociation. The question that remains then is whether the direct $\mathrm{CO}$ dissociation over highly active step-edges also maintains a low barrier at expected coverages of $\sim 0.6 \mathrm{ML}$.

\section{RESULTS AND DISCUSSION}

Because systematic computational data of coverage-dependent $\mathrm{CO}$ dissociation are lacking, we made a detailed comparison of this aspect for the low-reactive $\mathrm{Co}(0001)$ and high-reactive stepped $\operatorname{Co}(11 \overline{2} 1)$ surfaces using DFT (see the Supporting Information for computational details). While the $\mathrm{Co}(0001)$ surface is planar, the $\operatorname{Co}(11 \overline{2} 1)$ surface contains a twodimensional array of step-edge sites composed of a reactive pocket consisting of 5 cobalt atoms (Figure 1a, top left, $B_{5}$-site following the notation of Van Hardeveld and Hartog). ${ }^{50} \mathrm{We}$ first determined stable $\mathrm{CO}$ configurations as a function of total $\mathrm{CO}$ coverage (Figures $\mathrm{S} 1-\mathrm{S} 3$ ). We find that $\mathrm{CO}$ preferentially adsorbs in 3-fold hollow sites. This is in contrast to the topadsorption mode that is commonly observed in experiments. ${ }^{51}$ However, the computed difference in site preference is small, i.e., top-adsorbed $\mathrm{CO}$ is only $1 \mathrm{~kJ} / \mathrm{mol}$ less stable at a $1 / 3 \mathrm{ML}$ $\mathrm{CO}$ coverage on $\mathrm{Co}(0001)$. Overbinding and the incorrect site-preference prediction for $\mathrm{CO}$ have been frequently reported for GGA functionals like the PBE functional used here. $^{52}$ Although applying hybrid functionals like B3LYP ${ }^{53}$ or methods like $\mathrm{RPA}^{54}$ can in principle improve these results, the small differences observed in this study do not warrant the additional computational expenditure. The same holds for predicting the exact influence of lateral interactions. While there are various flavors of DFT functionals available, there is no universal one that can guarantee a highly accurate description of subtle coverage effects. Therefore, we first compared the overall changes in adsorption energies as a function of coverage. As expected, higher $\mathrm{CO}$ coverage leads to a lower average $\mathrm{CO}$ adsorption energy, which is in line with both experimental findings 42 and theoretical studies using different DFT functionals. ${ }^{43,55}$ Importantly, we find that the saturation coverage is $\sim 0.6 \mathrm{ML}$ for both surfaces. Notably, the differential $\mathrm{CO}$ adsorption energies for these surfaces show similar trends with $\mathrm{CO}$ coverage. Figure 1 shows the transition state for direct $\mathrm{CO}$ dissociation on the $\mathrm{Co}(11 \overline{2} 1)$ surface at a low 0.07 ML coverage. We compared direct and $\mathrm{H}$-assisted $\mathrm{CO}$ dissociation pathways at this coverage (Figure S4) and found that direct $\mathrm{CO}$ dissociation is the preferred pathway on this surface, in line with the work of Liu et al. ${ }^{27} \mathrm{CO}$ migrates from its most stable adsorption site to the $B_{5}$ site, where it is less stable by only $17 \mathrm{~kJ} / \mathrm{mol}$. From this state, dissociation can occur with a barrier of $83 \mathrm{~kJ} / \mathrm{mol}$. The overall activation barrier for $\mathrm{C}-\mathrm{O}$ bond dissociation is thus only $100 \mathrm{~kJ} / \mathrm{mol}$, which is sufficiently low to maintain a high rate of monomer formation. $^{18-21}$

Aiming at a deeper insight into this dissociation reaction, we also computed reaction energy diagrams at higher $\mathrm{CO}$ coverages $(0.30,0.44$, and $0.59 \mathrm{ML})$. The transition states at higher $\mathrm{CO}$ coverage are similar to those computed at $0.07 \mathrm{ML}$ coverage (Figure 1b). The same holds for the reaction pathways for $\mathrm{CO}$ dissociation on the close-packed $\mathrm{Co}(0001)$ surface (Figure 1c). Parts $\mathrm{d}$ and e of Figure 1 show the potential energy diagrams as a function of the $\mathrm{C}-\mathrm{O}$ distance, which is used here as the reaction coordinate. The reaction shifts from exothermic at low $\mathrm{CO}$ coverage to endothermic at high $\mathrm{CO}$ coverage, which is due to the stronger lateral interactions of the adsorbed $\mathrm{C}$ and $\mathrm{O}$ atoms compared to adsorbed $\mathrm{CO}$ at higher coverage. An important finding is that the $\mathrm{CO}$ dissociation barrier on the $\mathrm{Co}(11 \overline{2} 1)$ surface does not appreciably change with $\mathrm{CO}$ coverage. The variation of the activation barriers is within $14 \mathrm{~kJ} / \mathrm{mol}$ and remains below 100 $\mathrm{kJ} / \mathrm{mol}$ (Table S5). Figure 1e shows that the activation barrier for the $\mathrm{Co}(0001)$ surface increases from $225 \mathrm{~kJ} / \mathrm{mol}$ at a coverage of $0.11 \mathrm{ML}$ to $269 \mathrm{~kJ} / \mathrm{mol}$ at a coverage of $0.67 \mathrm{ML}$. The energy profiles in Figure 1 are relative to the electronic energy of the local initial state. This means that an additional reorientation may be necessary from the most stable adsorption configuration. This is mostly the case for the $\mathrm{Co}(11 \overline{2} 1)$ surface, as a properly located vacancy is needed, and the dissociating $\mathrm{CO}$ molecule is for most coverages more stable with the carbon atom in a 3-fold adsorption site (Figure S6). 
The energetic differences between these configurations are small compared to the dissociation barrier. This indicates that the computed site preference only has a small influence on the overall barrier. More importantly, the barriers referenced to the most stable adsorption configurations have the same coverage dependence as those referenced to the local initial states. Thus, whereas on a terrace Co surface a higher $\mathrm{CO}$ coverage leads to the expected increase of the activation barrier for $\mathrm{CO}$ dissociation, this reaction is hardly affected by $\mathrm{CO}$ coadsorbates on the step-edge site.

We analyzed the origin of these differences in more detail by studying the electronic structure along the dissociation pathway. Repulsive interactions due to coadsorbates can originate from through-space electron-electron repulsion with the dissociating $\mathrm{CO}$ molecule and from a decreased reactivity of surface metal atoms due to metal valence electron sharing between the dissociating molecule and coadsorbates. We addressed the latter aspect by computing bond orders along the reaction coordinate during dissociation using the recently introduced DDEC6 atomic population analysis, which allows accurate charge partitioning to assign net atomic charges. ${ }^{56}$ Figure 2 shows the bond orders of the dissociating
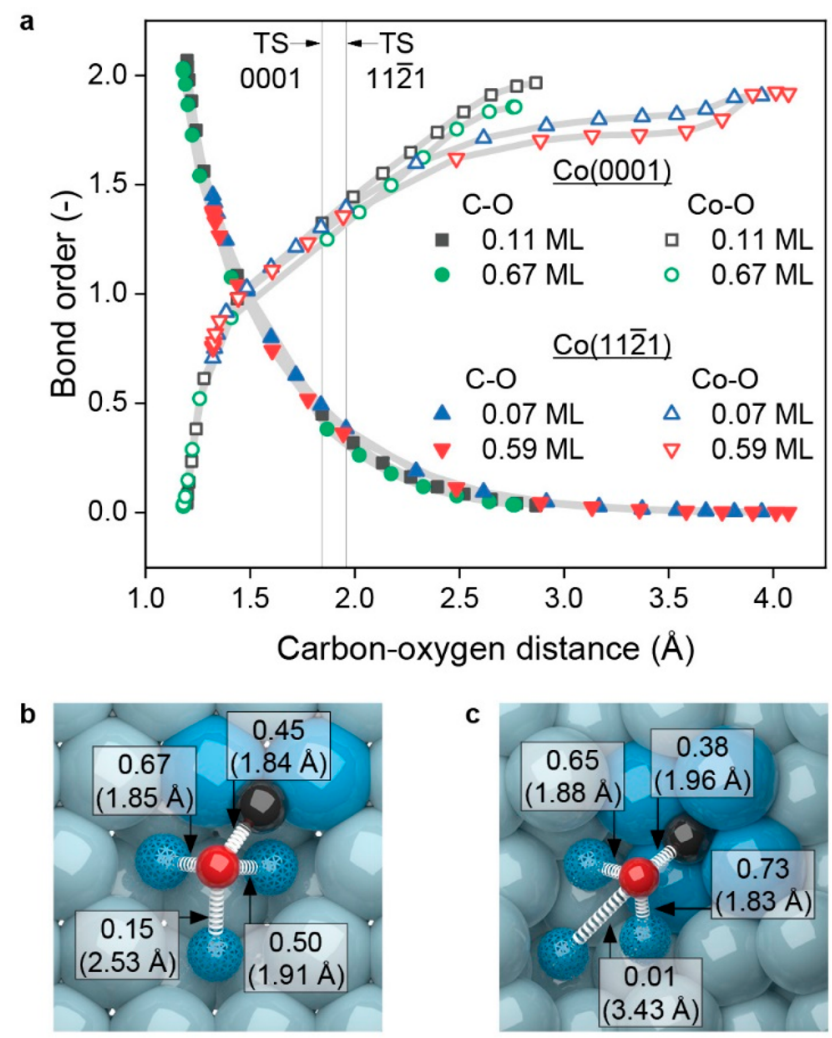

Figure 2. Bond orders determined by a DDEC6 atomic population analysis for $\mathrm{CO}$ dissociation on $\mathrm{Co}(11 \overline{2} 1)$ and $\mathrm{Co}(0001)$ at low and high coverage. The filled symbols in panel (a) represent the bond orders between the dissociating carbon-oxygen pair, and the open symbols represent the cumulative bond order of the dissociating oxygen atom with the three cobalt atoms to which the oxygen binds to in the final state. The locations of the two transition states are also indicated. Panels (b) and (c) show the individual bond orders and atom-atom distances at low coverage for the transition state on $\mathrm{Co}(0001)$ and $\mathrm{Co}(11 \overline{2} 1)$, respectively. The cobalt atoms accommodating the oxygen atom are shown with smaller spheres for improved clarity.
$\mathrm{CO}$ molecule and the $\mathrm{Co}-\mathrm{O}$ bonds, along the reaction coordinate. It can be seen that the $\mathrm{C}-\mathrm{O}$ bond order starts around 2.0 on the $\mathrm{Co}(0001)$ surface, while the $\mathrm{C}-\mathrm{O}$ bond on $\mathrm{Co}(11 \overline{2} 1)$ is already elongated and starts at 1.5 (bond order in free $\mathrm{CO}$ is 2.5). The bond orders then decrease to a value close to zero in the final state. Strikingly, the changes in the $\mathrm{C}-\mathrm{O}$ bond order do not depend on the CO coverage. Similarly, we find that the $\mathrm{Co}-\mathrm{O}$ bond orders increase in a very similar manner for the two investigated surfaces along the reaction coordinate. Only at the highest $\mathrm{CO}$ coverage, the $\mathrm{Co}-\mathrm{O}$ bond order is slightly lower in comparison to lower coverage. From these trends, we can infer that the sharing of valence electrons of the Co surface atoms involved in binding the $\mathrm{C}$ and $\mathrm{O}$ atoms is not strongly affected by $\mathrm{CO}$ coadsorbates and, therefore, cannot account for the stronger $\mathrm{CO}$ coverage dependence of $\mathrm{CO}$ dissociation on the $\mathrm{Co}(0001)$ surface.

To better understand the way through-space electronelectron repulsion from $\mathrm{CO}$ coadsorbates affects the activation barrier, we aimed for analyzing the Hartree potential along the reaction coordinate of $\mathrm{C}-\mathrm{O}$ bond dissociation. The Hartree potential $\left(V_{\text {Hartree }}\right)$ is defined as the electrostatic potential resulting from the electron charge density. This potential is repulsive, and larger values relate to regions of stronger Coulombic repulsion. In the VASP implementation of DFT, the Hartree potential cannot be separated from the attractive electron-ion potential $\left(V_{\text {ion }}\right)$. The combined potential is negative, wherein values closer to zero relate to regions less favorable for inserting electron density of nearby atoms. Accordingly, we sampled the combined Hartree and electronion potential $\left(V_{\text {Hartree }}+V_{\text {ion }}\right.$, hereafter called $\left.V_{\text {electrostatic }}\right)$ on a sphere with $0.75 \AA$ radius positioned concentric to the $\mathrm{O}$ atom of the dissociating $\mathrm{CO}$ molecule. We first focus on the differences for the two surfaces before discussing the coverage effects. Figure 3 shows that $V_{\text {electrostatic }}$ increases for all reaction pathways considered during the stretching of the $\mathrm{C}-\mathrm{O}$ bond. This increase is mainly due to the decreasing electron-ion attraction when the $\mathrm{C}-\mathrm{O}$ bond is elongated. Notably, there is a very steep increase of the electrostatic potential along the reaction coordinate for the $\mathrm{Co}(0001)$ surface, which corresponds to the bending of the $\mathrm{CO}$ molecule toward the surface. Comparison of the two cases shows-as habitually assumed-that the energy needed to bend the adsorbed $\mathrm{CO}$ molecule makes up a large part of the $\mathrm{CO}$ dissociation barrier difference between terrace and stepped surfaces. In the $B_{5}$ site on the $\mathrm{Co}(11 \overline{2} 1)$ surface, the $\mathrm{CO}$ molecule is already preactivated. After the transition state, $V_{\text {electrostatic }}$ becomes more negative for the $\mathrm{Co}(0001)$ surface, whereas there is a plateau for the $\mathrm{Co}(11 \overline{2} 1)$ surface. Inspection of the $\mathrm{C}-\mathrm{O}$ bond-dissociation pathways shows that the decrease is due to migration of the $\mathrm{O}$ atom from 2 -fold adsorption toward the final 3-fold adsorption site. The plateau for the $\operatorname{Co}(11 \overline{2} 1)$ surface corresponds to the migration of the $\mathrm{O}$ atom over the bridge site from one side of the step to the other side before the energy is lowered by movement into the 3-fold adsorption site. The final $\mathrm{C}-\mathrm{O}$ bond distance after dissociation is longer for the $\operatorname{Co}(11 \overline{2} 1)$ surface because of the different geometry of the step-edge.

Next, we consider the effect of coadsorbates. The findings above imply that the changes in the electrostatic potential brought about by coadsorbates should be predominantly the result of variations in the electron-electron repulsion. Figure 3 shows then that the electron-electron repulsion for $\mathrm{CO}$ dissociation on $\mathrm{Co}(0001)$ is significantly stronger at a high $\mathrm{CO}$ 

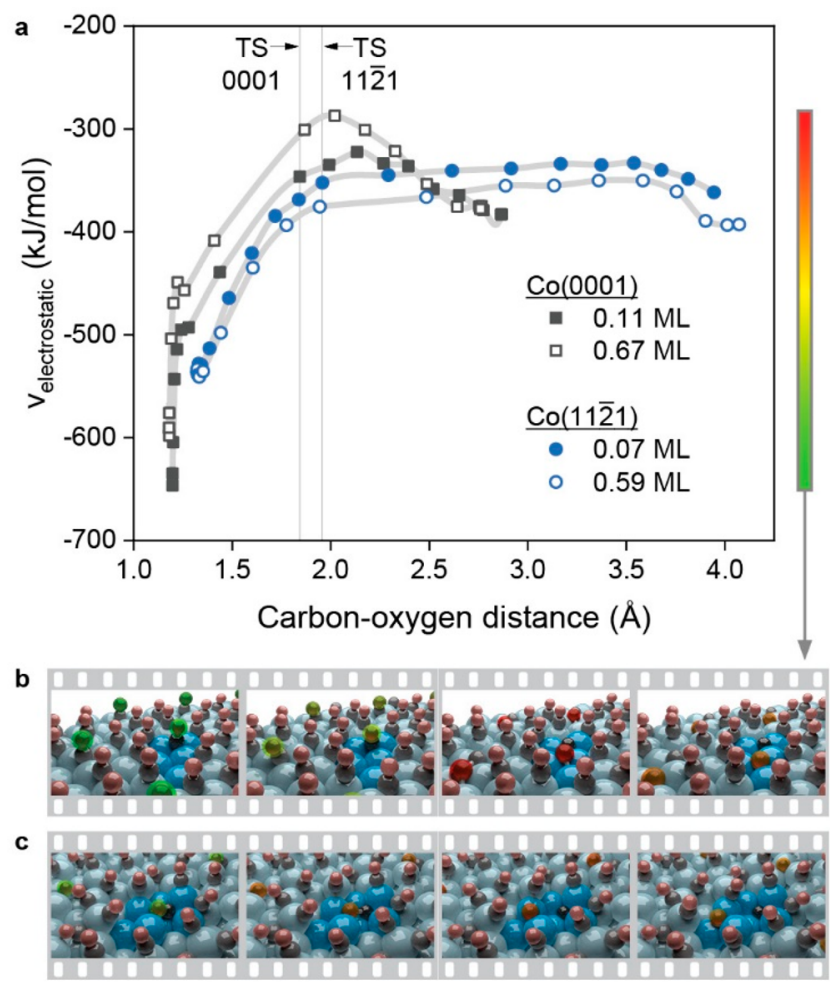

Figure 3. Electrostatic potential $\left(V_{\text {electrostatic }}\right.$ a combination of the electron-ion and the Hartree potential) along the $\mathrm{CO}$ dissociation pathway on the $\mathrm{Co}(11 \overline{2} 1)$ and $\mathrm{Co}(0001)$ surfaces at low and high $\mathrm{CO}$ coverage. The electrostatic potential was sampled on a sphere with $0.75 \AA$ radius positioned concentric to the $\mathrm{O}$ atom of the dissociating $\mathrm{CO}$ molecule. The lower panels show the color-coded value of the electrostatic potential on the $\mathrm{O}$ atom on (b) $\mathrm{Co}(0001)$ and (c) $\mathrm{Co}(11 \overline{2} 1)$. Movies of this potential are available online, as well as annotated still images (Figure S6-S7, Movies 1-4).

coverage. The corresponding data for $\mathrm{Co}(11 \overline{2} 1)$ surprisingly show that the electron-electron repulsion at higher coverage is not increased due to coadsorbates. These very different trends can well explain why $\mathrm{CO}$ bond dissociation is nearly unaffected by $\mathrm{CO}$ coadsorbates at the step-edge site. Analyzing the geometries along the reaction pathway, the possibility of $\mathrm{CO}$ coadsorbates to reorient at the step-edge site stands out over the rigid configuration of the adsorbed layer observed for the $\mathrm{Co}(0001)$ terrace at high $\mathrm{CO}$ coverage. The reorientation of the adsorbed layer at the step-edge site results in nearly similar electrostatic potentials at low and high coverages, both for the initial and the transition state. On $\mathrm{Co}(0001)$, this only holds for the final state. The reason is that in this case the oxygen atom obtained by $\mathrm{CO}$ dissociation is significantly closer to the surface than the oxygen atoms of the coadsorbed CO. Another possible effect is that the $\mathrm{CO}$ coadsorbates withdraw electron density from the two cobalt atoms at the top of the step-edge site, resulting in a larger cobalt-cobalt distance. This distance is $2.47 \AA$ at low coverage and increases to $2.58 \AA$ at high coverage, which can explain the reduced energy for the $\mathrm{O}$ atom to cross the bridged site.

Encouraged by these insights, we determined the reaction energetics of relevant elementary reaction steps for the FT reaction on the $\mathrm{Co}(11 \overline{2} 1)$ and $\mathrm{Co}(0001)$ surfaces and used these data as input to microkinetics simulations (Tables S1 and S2). The simulations were carried out under conditions relevant to FT synthesis $\left(\mathrm{H}_{2} / \mathrm{CO}=2,473-553 \mathrm{~K}, 1\right.$ bar $)$. We considered three different cases, namely, simulations for either the $\mathrm{Co}(0001)$ or the $\mathrm{Co}(11 \overline{2} 1)$ surface and simulations using a combination of these two surfaces in which we set the $\mathrm{Co}(0001) / \operatorname{Co}(11 \overline{2} 1)$ ratio to 10 . The site ratio is a conservative estimate of the abundance of step-edge sites at the optimum size of cobalt nanoparticles for FT synthesis. ${ }^{24}$ In the simulations involving the two cobalt surfaces, migration of $\mathrm{C}$ and $\mathrm{CH}_{x}$ species $(x=1-3)$ from the step-edge site to the terrace was taken into account.

Clearly, the high barrier for $\mathrm{CO}$ bond dissociation on $\mathrm{Co}(0001)$ results in a very low $\mathrm{CO}$ conversion rate (turnover frequency at $493 \mathrm{~K}, \mathrm{TOF}_{493 \mathrm{~K}}=10^{-8} \mathrm{~s}^{-1}$ ), and the main product is methane (selectivity $>99 \%$ ). The CO conversion rate for the $\operatorname{Co}(11 \overline{2} 1)$ surface is much higher. The predicted TOF at $493 \mathrm{~K}$ is $0.01 \mathrm{~s}^{-1}$, which is in good agreement with surface cobalt atom normalized experimental data. ${ }^{23}$ The product distribution (Figure $4 \mathrm{a}$ ) is also consistent with
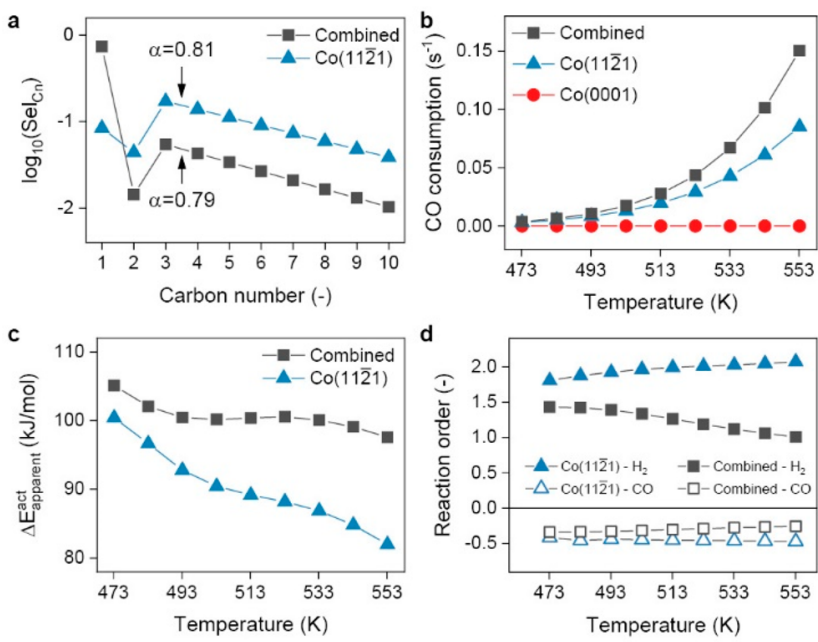

Figure 4. Microkinetic simulations of the FT synthesis reaction (1 bar, $\left.\mathrm{H}_{2} / \mathrm{CO}=2\right)$ on $\mathrm{Co}(11 \overline{2} 1), \mathrm{Co}(0001)$, and combined $\mathrm{Co}(11 \overline{2} 1)$ / $\mathrm{Co}(0001)$ surfaces: (a) Anderson-Schulz-Flory (ASF) plot at $493.15 \mathrm{~K}$ for the $\mathrm{Co}(11 \overline{2} 1)$ and the combined surfaces; (b) $\mathrm{CO}$ consumption rates for the three cases considered; (c) apparent activation energy for $\mathrm{Co}(11 \overline{2} 1)$ and the combined surfaces; (d) reaction orders for the $\mathrm{Co}(11 \overline{2} 1)$ and the combined surfaces.

experimental data. The chain-growth probability is 0.81 , and a low $\mathrm{C}_{2}$-selectivity is predicted. The methane selectivity is relatively low, indicating that the strong binding of $\mathrm{C}$ intermediates at step-edge sites suppresses methanation. The analysis of the product distribution over the isolated $\mathrm{Co}(0001)$ is not shown in Figure 4, because the corresponding rate is negligible and only methane is formed. Interestingly, when the two surfaces are coupled through migration of surface $\mathrm{C}$ and $\mathrm{CH}_{x}$ species, we observe that the methane selectivity increases, while the chain growth probability decreases to 0.79 . Analysis of the reaction network shows that these changes are predominantly due to the migration of $\mathrm{CH}_{3}$ species from the step-edge to the terrace surface. This migration also affects the apparent activation energy (Figure 4c), which is consistent with the experimental findings reported in Figure 1 in the work of Chen et al. ${ }^{19}$ In that study, the apparent activation energy based only on the TOF of $\mathrm{CH}_{4}$ (Figure $1 \mathrm{~b}$ ) is $>100 \mathrm{~kJ} / \mathrm{mol}$, whereas the activation energy based on the total $\mathrm{CO}$ conversion ranges from 57 to $74 \mathrm{~kJ} / \mathrm{mol}$ (Figure 1a). This indicates that the apparent activation energy will increase for 
systems with higher $\mathrm{CH}_{4}$ selectivity. Without migration of $\mathrm{CH}_{x}$ species, carbon species accumulate on the $\mathrm{Co}(11 \overline{2} 1)$ surface and termination reactions become more rate-controlling. The poisoning by hydrocarbon species is expected to increase at higher temperatures, which is in line with the stronger temperature dependency of the apparent activation energy and the higher hydrogen reaction orders for the $\operatorname{Co}(11 \overline{2} 1)$ case (Figure 4d). Yates and Satterfield reported apparent activation energies of $93-103 \mathrm{~kJ} / \mathrm{mol}$ for a wide range of studied conditions. ${ }^{57}$ Our model predictions are in good agreement with these findings as well as the experimentally observed negative reaction order in $\mathrm{CO}^{58}$ An important point here is that the negative $\mathrm{CO}$ reaction order does not imply that a $\mathrm{CO}$ needs to desorb every time that a dissociation event occurs. This would be the case for a fully covered surface, for which the reaction order with respect to $\mathrm{CO}$ has to be -1 . The less negative reaction order in $\mathrm{CO}$ observed here can be explained by a changing number of empty sites as a function of $\mathrm{CO}$ partial pressure. Under realistic conditions there will be empty sites available for direct $\mathrm{CO}$ dissociation. With increasing $\mathrm{CO}$ partial pressure, more $\mathrm{CO}$ will adsorb at the expense of empty sites. Although a steep increase in CO coverage is counteracted by an increase in lateral repulsions, the relative decrease in the number of free sites is expected to be more significant. Thus, the reaction rate will decrease, explaining the negative reaction order in CO. As in most studies, the work of Yates and Satterfield indicates a hydrogen reaction order not higher than unity, while our microkinetic model exceeds this value. We surmise that this inconsistency is caused by an overestimation in our microkinetic model of hydrocarbons buildup on the step-edge surface, possibly because we neglect the effect of lateral interactions on termination reactions. A relative stabilization of hydrogenated species over coadsorbed hydrogen would promote these steps and would be a topic for further investigation into the promotion of hydrogen-assisted mechanisms of $\mathrm{CO}$ scission. Furthermore, although we corrected for the small change in the adsorption heat between $\mathrm{C}_{2}$ and $\mathrm{C}_{3+}$ hydrocarbons, ${ }^{59}$ we did not yet correct in detail the hydrogenation and coupling steps of these species. Nevertheless, the relatively simple model provided here can already explain a wide range of experimental kinetic data for cobalt catalysts and can well explain recent experimental findings of lowered methane selectivity upon selective poisoning of the cobalt terrace surface. ${ }^{15}$

\section{CONCLUSIONS}

DFT-computed reaction barriers reveal that step-edge sites remain highly active for direct $\mathrm{CO}$ dissociation at the high $\mathrm{CO}$ coverages relevant to practical FT synthesis. On the contrary, the further reduced rate of direct $\mathrm{CO}$ scission on terrace sites suggests that the much slower dissociation on those sites will proceed through a hydrogen-assisted pathway. We investigated the electronic structure along the direct $\mathrm{CO}$ dissociation pathway on step-edge and terrace cobalt surfaces. We find that the sharing of valence electrons of the cobalt surface atoms involved in binding the $\mathrm{C}$ and $\mathrm{O}$ atoms is not strongly affected by $\mathrm{CO}$ coadsorbates and, therefore, cannot account for the differences in $\mathrm{CO}$ coverage dependence. A deep analysis of the electronic structure around the dissociating oxygen atom reveals significant differences of the electrostatic potential on the oxygen atom of the dissociating $\mathrm{CO}$ molecule between the two surfaces. The higher flexibility of the adsorbed $\mathrm{CO}$ layer on the corrugated stepped surface weakens lateral interactions and explains the lower dissociation barrier compared to the terrace surface that has a more rigid $\mathrm{CO}$ adsorbed layer. By integrating these barriers in a microkinetic model of FT synthesis, we not only show that experimentally observed rates can be reproduced but also can appreciate how migration of $\mathrm{CH}_{x}$ species between step-edge and terrace sites can explain high rates of methane formation.

\section{ASSOCIATED CONTENT}

\section{S Supporting Information}

The Supporting Information is available free of charge on the ACS Publications website at DOI: 10.1021/acscatal.9b01967.

Computational methods, elementary reaction steps, and adsorption energies (PDF)

Movies of the electrostatic potential along the $\mathrm{CO}$ dissociation pathway. Movie 1 (MP4)

Movie 2 (MP4)

Movie 3 (MP4)

Movie 4 (MP4)

\section{AUTHOR INFORMATION}

\section{Corresponding Author}

*E-mail: e.j.m.hensen@tue.nl.

\section{ORCID $\odot$}

Bart Zijlstra: 0000-0002-4040-6545

Robin J. P. Broos: 0000-0002-2580-5468

Emiel J. M. Hensen: 0000-0002-9754-2417

Notes

The authors declare no competing financial interest.

\section{ACKNOWLEDGMENTS}

The authors gratefully acknowledge financial support from Shell Global Solutions International B.V. The Netherlands Organization for Scientific Research is acknowledged for providing access to computational resources.

\section{REFERENCES}

(1) van Santen, R. A. Catalytic Paradigms: A Riddle and a Puzzle. Angew. Chem., Int. Ed. 2014, 53, 8618-20.

(2) Ferrin, P.; Simonetti, D.; Kandoi, S.; Kunkes, E.; Dumesic, J. A.; Norskov, J. K.; Mavrikakis, M. Modeling Ethanol Decomposition on Transition Metals: A Combined Application of Scaling and BronstedEvans-Polanyi Relations. J. Am. Chem. Soc. 2009, 131, 5809-15.

(3) Latimer, A. A.; Kulkarni, A. R.; Aljama, H.; Montoya, J. H.; Yoo, J. S.; Tsai, C.; Abild-Pedersen, F.; Studt, F.; Nørskov, J. K. Understanding Trends in $\mathrm{C}-\mathrm{H}$ Bond Activation in Heterogeneous Catalysis. Nat. Mater. 2017, 16, 225.

(4) Norskov, J. K.; Bligaard, T.; Rossmeisl, J.; Christensen, C. H. Towards the Computational Design of Solid Catalysts. Nat. Chem. 2009, 1, 37-46.

(5) van Santen, R. A.; Neurock, M.; Shetty, S. G. Reactivity Theory of Transition-Metal Surfaces: A Bronsted-Evans-Polanyi Linear Activation Energy-Free-Energy Analysis. Chem. Rev. 2010, 110, 2005-48.

(6) Eyring, H. The Activated Complex and the Absolute Rate of Chemical Reactions. Chem. Rev. 1935, 17, 65-77.

(7) Filot, I. A.; van Santen, R. A.; Hensen, E. J. The Optimally Performing Fischer-Tropsch Catalyst. Angew. Chem., Int. Ed. 2014, 53, 12746-12750.

(8) Liu, X.; Xiao, J.; Peng, H.; Hong, X.; Chan, K.; Norskov, J. K. Understanding Trends in Electrochemical Carbon Dioxide Reduction Rates. Nat. Commun. 2017, 8, 15438. 
(9) Langmuir, I. The Mechanism of the Catalytic Action of Platinum in the Reactions $2 \mathrm{co}+\mathrm{O} 2=2 \mathrm{co} 2$ and $2 \mathrm{~h} 2+\mathrm{O} 2=2 \mathrm{~h} 2 \mathrm{o}$. Trans. Faraday Soc. 1922, 17, 621-621.

(10) Taylor, H. S. A Theory of the Catalytic Surface. Proc. R. Soc. London, Ser. A 1925, 108, 105-111.

(11) Honkala, K.; Hellman, A.; Remediakis, I. N.; Logadottir, A.; Carlsson, A.; Dahl, S.; Christensen, C. H.; Nørskov, J. K. Ammonia Synthesis from First-Principles Calculations. Science 2005, 307, 555558.

(12) Zhuo, M.; Borgna, A.; Saeys, M. Effect of the Co Coverage on the Fischer-Tropsch Synthesis Mechanism on Cobalt Catalysts. J. Catal. 2013, 297, 217-226.

(13) Loveless, B. T.; Buda, C.; Neurock, M.; Iglesia, E. Co Chemisorption and Dissociation at High Coverages During Co Hydrogenation on Ru Catalysts. J. Am. Chem. Soc. 2013, 135, 610721.

(14) Van Der Laan, G. P.; Beenackers, A. A. C. M. Kinetics and Selectivity of the Fischer-Tropsch Synthesis: A Literature Review. Catal. Rev.: Sci. Eng. 1999, 41, 255-318.

(15) Chen, W.; Kimpel, T. F.; Song, Y.; Chiang, F. K.; Zijlstra, B.; Pestman, R.; Wang, P.; Hensen, E. J. M. Influence of Carbon Deposits on the Cobalt-Catalyzed Fischer-Tropsch Reaction: Evidence of a Two-Site Reaction Model. ACS Catal. 2018, 8, 1580-1590.

(16) Sun, X.; Suarez, A. I. O.; Meijerink, M.; van Deelen, T.; OuldChikh, S.; Zecevic, J.; de Jong, K. P.; Kapteijn, F.; Gascon, J. Manufacture of Highly Loaded Silica-Supported Cobalt FischerTropsch Catalysts from a Metal Organic Framework. Nat. Commun. 2017, 8, 1680

(17) Navarro, V.; van Spronsen, M. A.; Frenken, J. W. In Situ Observation of Self-Assembled Hydrocarbon Fischer-Tropsch Products on a Cobalt Catalyst. Nat. Chem. 2016, 8, 929-34.

(18) Shetty, S. G.; Ciobica, I. M.; Hensen, E. J.; van Santen, R. A. Site Regeneration in the Fischer-Tropsch Synthesis Reaction: A Synchronized Co Dissociation and C-C Coupling Pathway. Chem. Commun. 2011, 47, 9822-4.

(19) Chen, W.; Filot, I. A. W.; Pestman, R.; Hensen, E. J. M. Mechanism of Cobalt-Catalyzed Co Hydrogenation: 2. FischerTropsch Synthesis. ACS Catal. 2017, 7, 8061-8071.

(20) Liu, Z.-P.; Hu, P. A New Insight into Fischer-Tropsch Synthesis. J. Am. Chem. Soc. 2002, 124, 11568-11569.

(21) Ge, Q.; Neurock, M.; Wright, H. A.; Srinivasan, N. A First Principles Study of Carbon-Carbon Coupling over the $\{0001\}$ Surfaces of Co and Ru. J. Phys. Chem. B 2002, 106, 2826-2829.

(22) Quek, X. Y.; Filot, I. A.; Pestman, R.; van Santen, R. A.; Petkov, V.; Hensen, E. J. Correlating Fischer-Tropsch Activity to Ru Nanoparticle Surface Structure as Probed by High-Energy X-Ray Diffraction. Chem. Commun. 2014, 50, 6005-8.

(23) Bezemer, G. L.; Bitter, J. H.; Kuipers, H. P.; Oosterbeek, H.; Holewijn, J. E.; Xu, X.; Kapteijn, F.; van Dillen, A. J.; de Jong, K. P. Cobalt Particle Size Effects in the Fischer-Tropsch Reaction Studied with Carbon Nanofiber Supported Catalysts. J. Am. Chem. Soc. 2006, $128,3956-64$

(24) van Helden, P.; Ciobîcă, I. M.; Coetzer, R. L. J. The SizeDependent Site Composition of Fcc Cobalt Nanocrystals. Catal. Today 2016, 261, 48-59.

(25) Ligthart, D. A. J. M.; Filot, I. A. W.; Almutairi, A. A. H.; Hensen, E. J. M. Identification of Step-Edge Sites on Rh Nanoparticles for Facile Co Dissociation. Catal. Commun. 2016, 77, 5-8.

(26) Petersen, M. A.; van den Berg, J. A.; Ciobica, I. M.; van Helden, P. Revisiting Co Activation on Co Catalysts: Impact Sites from Dft of Step and Kink. ACS Catal. 2017, 7, 1984-1992.

(27) Liu, J. X.; Su, H. Y.; Sun, D. P.; Zhang, B. Y.; Li, W. X. Crystallographic Dependence of Co Activation on Cobalt Catalysts: Hcp Versus Fcc. J. Am. Chem. Soc. 2013, 135, 16284-7.

(28) Filot, I. A. W.; van Santen, R. A.; Hensen, E. J. M. Quantum Chemistry of the Fischer-Tropsch Reaction Catalysed by a Stepped Ruthenium Surface. Catal. Sci. Technol. 2014, 4, 3129-3140.
(29) Shetty, S.; Jansen, A. P.; van Santen, R. A. Direct Versus Hydrogen-Assisted Co Dissociation. J. Am. Chem. Soc. 2009, 131, 12874-5.

(30) van Helden, P.; van den Berg, J.-A.; Ciobîcă, I. M. HydrogenAssisted Co Dissociation on the Co(211) Stepped Surface. Catal. Sci. Technol. 2012, 2, 491.

(31) Ojeda, M.; Nabar, R.; Nilekar, A. U.; Ishikawa, A.; Mavrikakis, M.; Iglesia, E. Co Activation Pathways and the Mechanism of Fischer-Tropsch Synthesis. J. Catal. 2010, 272, 287-297.

(32) Zhao, Y.-H.; Liu, J.-X.; Su, H.-Y.; Sun, K.; Li, W.-X. A FirstPrinciples Study of Carbon-Oxygen Bond Scission in Multiatomic Molecules on Flat and Stepped Metal Surfaces. ChemCatChem 2014, 6, 1755-1762.

(33) Shetty, S.; van Santen, R. A. Hydrogen Induced Co Activation on Open Ru and Co Surfaces. Phys. Chem. Chem. Phys. 2010, 12, 6330-2.

(34) Filot, I. A. W.; Broos, R. J. P.; van Rijn, J. P. M.; van Heugten, G. J. H. A.; van Santen, R. A.; Hensen, E. J. M. First-Principles-Based Microkinetics Simulations of Synthesis Gas Conversion on a Stepped Rhodium Surface. ACS Catal. 2015, 5, 5453-5467.

(35) Liu, J.-X.; Su, H.-Y.; Li, W.-X. Structure Sensitivity of Co Methanation on Co (0001), ( $\left(\begin{array}{llll}1 & 0 & \overline{1} & 2\end{array}\right)$ and $\left(\begin{array}{llll}1 & 1 & \overline{2} & 0\end{array}\right)$ Surfaces: Density Functional Theory Calculations. Catal. Today 2013, 215, 36-42.

(36) Moodley, D. J.; van de Loosdrecht, J.; Saib, A. M.; Overett, M. J.; Datye, A. K.; Niemantsverdriet, J. W. Carbon Deposition as a Deactivation Mechanism of Cobalt-Based Fischer-Tropsch Synthesis Catalysts under Realistic Conditions. Appl. Catal., A 2009, 354, 102110.

(37) Fei Tan, K.; Xu, J.; Chang, J.; Borgna, A.; Saeys, M. Carbon Deposition on Co Catalysts During Fischer-Tropsch Synthesis: A Computational and Experimental Study. J. Catal. 2010, 274, 121129.

(38) Vendelbo, S. B.; Johansson, M.; Mowbray, D. J.; Andersson, M. P.; Abild-Pedersen, F.; Nielsen, J. H.; Norskov, J. K.; Chorkendorff, I. Self Blocking of Co Dissociation on a Stepped Ruthenium Surface. Top. Catal. 2010, 53, 357-364.

(39) Hibbitts, D.; Dybeck, E.; Lawlor, T.; Neurock, M.; Iglesia, E. Preferential Activation of Co near Hydrocarbon Chains During Fischer-Tropsch Synthesis on Ru. J. Catal. 2016, 337, 91-101.

(40) Chen, W.; Zijlstra, B.; Filot, I. A. W.; Pestman, R.; Hensen, E. J. M. Mechanism of Carbon Monoxide Dissociation on a Cobalt Fischer-Tropsch Catalyst. Chem CatChem 2018, 10, 136-140.

(41) Lahtinen, J.; Vaari, J.; Kauraala, K. Adsorption and Structure Dependent Desorption of Co on Co(0001). Surf. Sci. 1998, 418, $502-510$.

(42) Weststrate, C. J.; van de Loosdrecht, J.; Niemantsverdriet, J. W. Spectroscopic Insights into Cobalt-Catalyzed Fischer-Tropsch Synthesis: A Review of the Carbon Monoxide Interaction with Single Crystalline Surfaces of Cobalt. J. Catal. 2016, 342, 1-16.

(43) Gunasooriya, G. T. K. K.; van Bavel, A. P.; Kuipers, H. P. C. E.; Saeys, M. Co Adsorption on Cobalt: Prediction of Stable Surface Phases. Surf. Sci. 2015, 642, L6-L10.

(44) Yang, J.; Frøseth, V.; Chen, D.; Holmen, A. Particle Size Effect for Cobalt Fischer-Tropsch Catalysts Based on in Situ Co Chemisorption. Surf. Sci. 2016, 648, 67-73.

(45) den Breejen, J. P.; Radstake, P. B.; Bezemer, G. L.; Bitter, J. H.; Froseth, V.; Holmen, A.; de Jong, K. P. On the Origin of the Cobalt Particle Size Effects in Fischer-Tropsch Catalysis. J. Am. Chem. Soc. 2009, 131, 7197-203.

(46) Liu, J.; Hibbitts, D.; Iglesia, E. Dense Co Adlayers as Enablers of Co Hydrogenation Turnovers on Ru Surfaces. J. Am. Chem. Soc. 2017, 139, 11789-11802.

(47) Hibbitts, D. D.; Loveless, B. T.; Neurock, M.; Iglesia, E. Mechanistic Role of Water on the Rate and Selectivity of FischerTropsch Synthesis on Ruthenium Catalysts. Angew. Chem., Int. Ed. 2013, 52, 12273-8.

(48) Niemantsverdriet, H.; van Helden, P.; Hensen, E.; Lennon, D.; Holt, K.; Hutchings, G.; Bowker, M.; Catlow, R.; Shozi, M.; Jewell, L.; Claeys, M.; Hayward, J.; Coville, N.; Fischer, N.; Roldan, A.; 
Redekop, E.; Gambu, T.; Deeplal, L.; Mkhwanazi, T. P. O.; Weststrate, K. J.; Bahnemann, D.; Neurock, M.; Schulz, H.; Ma, D.; Kondrat, S.; Collier, P.; Gupta, A. K.; Corma, A.; Akomeah, P.; Iglesia, E.; van Steen, E.; de Leeuw, N.; Wolf, M.; van Heerden, T. Catalysis for Fuels: General Discussion. Faraday Discuss. 2017, 197, 165-205.

(49) Su, H.-Y.; Zhao, Y.; Liu, J.-X.; Sun, K.; Li, W.-X. First-Principles Study of Structure Sensitivity of Chain Growth and Selectivity in Fischer-Tropsch Synthesis Using Hcp Cobalt Catalysts. Catal. Sci. Technol. 2017, 7, 2967-2977.

(50) Van Hardeveld, R.; Hartog, F. The Statistics of Surface Atoms and Surface Sites on Metal Crystals. Surf. Sci. 1969, 15, 189-230.

(51) Lahtinen, J.; Vaari, J.; Kauraala, K.; Soares, E. A.; Van Hove, M. A. Leed Investigations on $\mathrm{Co}(0001)$ : The $(3 \times 3) \mathrm{R} 30^{\circ}$-Co Overlayer. Surf. Sci. 2000, 448, 269-278.

(52) Feibelman, P. J.; Hammer, B.; Nørskov, J. K.; Wagner, F.; Scheffler, M.; Stumpf, R.; Watwe, R.; Dumesic, J. The Co/Pt(111) Puzzle. J. Phys. Chem. B 2001, 105, 4018-4025.

(53) Gil, A.; Clotet, A.; Ricart, J. M.; Kresse, G.; Garc1, x; aHernández, M.; Rösch, N.; Sautet, P. Site Preference of Co Chemisorbed on $\mathrm{Pt}(111)$ from Density Functional Calculations. Surf. Sci. 2003, 530, 71-87.

(54) Schimka, L.; Harl, J.; Stroppa, A.; Grüneis, A.; Marsman, M.; Mittendorfer, F.; Kresse, G. Accurate Surface and Adsorption Energies from Many-Body Perturbation Theory. Nat. Mater. 2010, 9, 741.

(55) Grabow, L. C.; Hvolbæk, B.; Nørskov, J. K. Understanding Trends in Catalytic Activity: The Effect of Adsorbate-Adsorbate Interactions for Co Oxidation over Transition Metals. Top. Catal. 2010, 53, 298-310.

(56) Manz, T. A. Introducing Ddec6 Atomic Population Analysis: Part 3. Comprehensive Method to Compute Bond Orders. RSC Adv. 2017, 7, 45552-45581.

(57) Yates, I. C.; Satterfield, C. N. Intrinsic Kinetics of the FischerTropsch Synthesis on a Cobalt Catalyst. Energy Fuels 1991, 5, 168173.

(58) Ma, W.; Jacobs, G.; Sparks, D. E.; Gnanamani, M. K.; Pendyala, V. R. R.; Yen, C. H.; Klettlinger, J. L. S.; Tomsik, T. M.; Davis, B. H. Fischer-Tropsch Synthesis: Support and Cobalt Cluster Size Effects on Kinetics over $\mathrm{Co} / \mathrm{Al} 2 \mathrm{o} 3$ and $\mathrm{Co} / \mathrm{Sio} 2$ Catalysts. Fuel 2011, 90, $756-765$.

(59) Qi, Y.; Ledesma, C.; Yang, J.; Duan, X.; Zhu, Y.-A.; Holmen, A.; Chen, D. Adsorption Energy-Driven Carbon Number-Dependent Olefin to Paraffin Ratio in Cobalt-Catalyzed Fischer-Tropsch Synthesis. J. Catal. 2017, 349, 110-117. 